ISSN: 0210-1696

DOI: http://dx.doi.org/10.14201/scero20154627997

\title{
¿DISCAPACIDAD O DIVERSIDAD FUNCIONAL?
}

\section{Disability or functional diversity?}

Joan CANimas Brugué

Observatorio de Ética Aplicada a la Acción Social, Psicoeducativa y Sociosanitaria. Fundación Campus Arnau d'Escala - Universidad de Girona. Parque Científico y Tecnológico UdG. joan. canimas@udg.edu

Recepción: 17 de diciembre de 2014

Fecha de aceptación definitiva: 25 de marzo de 2015

Biblid. [0210-1696 (2015) vol. 46 (2), n. ${ }^{\circ} 254$, abril-junio; 79-97]

Resumen: Hasta hoy disponemos de tres paradigmas para pensar lo que aún llamamos discapacidad: el médico, el social y el biopsicosocial (que ha intentado integrar y superar la confrontación entre los dos primeros). El Foro de Vida Independiente (FVI) y los autores y activistas que ayudan a profundizar y a extender sus propuestas celebran el avance que ha supuesto el paradigma biopsicosocial, pero no lo comparten y proponen un nuevo modelo que llaman de la diversidad funcional, una versión hermenéutica del paradigma social.

Este artículo intenta identificar los problemas que el modelo de la diversidad funcional plantea a la ética aplicada, y se centra en dos de ellos. El primero es: si lo que ahora consideramos deficiencia es interpretado únicamente como diversidad, ¿qué argumentos tendríamos para no respetar la decisión de unos padres de no corregir una deficiencia física, intelectual o del desarrollo de sus hijos, pudiéndolo hacer con una terapia eficaz, razonable y sin riesgos? ¿Y para impedir que les produzcan una deficiencia? El segundo problema es: ¿Cómo justificar la necesidad de discriminación positiva (más recursos y atenciones y más investigación médica y tecnológica a las personas con diversidad funcional) e incluso de apoyo, si se considera que su manera de funcionar no es ni mejor ni peor que las otras?

Palabras clave: discapacidad; diversidad funcional; ética; filosofía moral; definición; paradigma; Foro de Vida Independiente.

AвsTRAct: Currently, there are three approaches we can use to discuss what is still labelled as disability: medical, social and biopsychosocial (the latter being an attempt 
to integrate and ameliorate the conflict between the first two). The Foro de Vida Independiente (FVI) [Forum for Independent Living], and the authors and activists who help to expand their proposals, celebrate the significant progress achieved by the biopsychosocial approach, but remain dissatisfied with it and propose a new model called functional diversity, a hermeneutic version of the social approach.

This article attempts to identify the problems that the model of functional diversity poses to applied ethics, focussing in particular on two issues. The first is: if we now consider that an impairment should be interpreted only as diversity, What arguments would we have against parental decisions not to correct a physical, intellectual or developmental impairment in their children even though such an intervention were effective, reasonable and safe? And what arguments would we have in order to avoid those parents causing them an impairment? The second problem is: How can we justify the need for affirmative action (more resources and attention, more medical and technological research for people with functional diversity) or even justify providing support, if we consider that their way of functioning is not better or worse than any other?

KEY wORDs: disability; functional diversity; ethics; moral philosophy; definition; approach; Forum for Independent Living.

\section{Los paradigmas médico, social y biopsicosocial}

H

ASTA HOY, DISPONEMOS DE TRES PARADIgMAS para pensar la discapacidad: el médico, el social y el biopsicosocial ${ }^{1}$. En palabras de la Clasificación Internacional del Funcionamiento, de la Discapacidad y de la Salud (CIF) (OMS, 2001), el paradigma médico (que también ha sido llamado médico-rehabilitador) considera la discapacidad como un problema de la persona causado por una enfermedad, trauma o condición de salud, que requiere cuidados sanitarios prestados en forma de tratamiento individual. En este sistema, el tratamiento de la discapacidad está encaminado a conseguir el máximo cuidado posible y una mejor adaptación y respuesta de la persona a su situación.

Para el paradigma social, en cambio, la discapacidad no es un atributo de la persona, sino un problema social y político causado por las barreras y la marginación de las sociedades hacia aquellas personas que no tienen las condiciones que se consideran normales y deseables. Para este paradigma, el tratamiento del problema requiere las modificaciones ambientales, culturales y políticas necesarias para hacer posible la plena participación de cualquier persona en todas las áreas de la vida, sean cuales sean sus capacidades. El paradigma social se inició en la década de 1970 en el Reino Unido en movimientos como Union of the Physically Impaired Against Segregation (UPIAS) y Liberation Network of People with Disabilities (Campbell y Oliver, 1996;

1 José Antonio Seonne (2011) habla de cuatro modelos: médico, social, de la diversidad y de los derechos, el último de los cuales sería una síntesis de los tres primeros. Sin entrar en los distintos significados que puedan darse a los conceptos paradigma y modelo y a pesar de que el modelo de la diversidad se presenta, en algunas ocasiones, como un nuevo paradigma (PAlacios y Romañach, 2006: 169), hay razones para considerar que éste se mantiene dentro de los límites del paradigma social, si bien en su vertiente más hermenéutica, como se intentará demostrar en estas páginas. 
Longmore y Umansky, 2000). Desde entonces y a mi entender, han confluido en él al menos tres grandes tendencias: el materialismo histórico, que explica la opresión de las personas con discapacidad en el hecho de que no responden al valor capitalista de cuerpos productivos y funcionales; el feminismo y levinasismo, que la explican en términos de imposibilidad de reconocer al otro en su radical singularidad; y el nietzscheismo y foucaultismo más o menos constructivista (o postestructuralista), que explican la opresión en términos de imposición interpretativa de la mayoría. No me es posible desarrollar y fundamentar aquí esta tesis, sin embargo, espero mostrar, al menos, que el modelo de la diversidad funcional, en el que me centraré, se sitúa en la tendencia nietzscheana del paradigma social que llamaré social-hermenéutica.

Tal como señala Ramón Puig (1990), la Clasificación Internacional de Deficiencias, Discapacidades y Minusvalías (CIDDM) (OMS, 1980) supuso el primer intento de superación de la confrontación entre los paradigmas médico y social, que él denominó, siguiendo a Gerben DeJong (1979), de la rehabilitación y de la autonomía personal, respectivamente. Sin embargo, deberá esperarse a la Clasificación Internacional del Funcionamiento, de la Discapacidad y de la Salud (CIF) (OMS, 2001) para que se hable abiertamente y en estos términos de la integración de los paradigmas médico y social en el enfoque biopsicosocial. Esta nueva visión de la CIF se fundamenta en la diferenciación entre deficiencia (impairment) y discapacidad (disability): considera que la deficiencia es una anomalía o anormalidad en las funciones o estructuras corporales que dificulta o impide realizar acciones que se consideran valiosas (tal como defiende el paradigma médico), y la discapacidad la interacción de esta deficiencia con el mundo (tal como defiende el paradigma social), de tal manera que una misma deficiencia puede convertirse o no en una discapacidad, o puede serlo en distinto grado, según en quién y dónde se dé. Así pues, una misma deficiencia puede ser nada o más o menos incapacitante dependiendo de la clase social, el lugar y la época a la que pertenece la persona o personas que la tienen. Por ejemplo: la miopía es una deficiencia visual, pero si se dispone de las gafas adecuadas y la sociedad en la que se vive no margina o estigmatiza, de una u otra forma, a las personas que las llevan, no se tiene ninguna discapacidad.

La Convención sobre los derechos de las personas con discapacidad (ONU, 2006) recoge perfectamente el paradigma biopsicosocial propuesto por la CIF. En el Preámbulo, reconoce "que la discapacidad es un concepto que evoluciona y que resulta de la interacción entre las personas con deficiencias y las barreras debidas a la actitud y al entorno que evitan su participación plena y efectiva en la sociedad, en igualdad de condiciones con las demás", y en el artículo 1 que "Las personas con discapacidad incluyen a aquellas que tengan deficiencias físicas, mentales, intelectuales o sensoriales a largo plazo que, al interactuar con diversas barreras, puedan impedir su participación plena y efectiva en la sociedad, en igualdad de condiciones con las demás”2.

2 Para adentrarse en el desarrollo de los términos y paradigmas del ámbito de la discapacidad, pueden consultarse: Puig de la Bellacasa (1990); Casado (2001); Luckasson et al. (2002); Crespo, Campo y Verdugo (2003); Schalock (2007); Palacios (2008); Wehmeyer (2008); Schalock et al. (2010); Verdugo y Schalock (2010).

(C) Ediciones Universidad de Salamanca

Siglo Cero, vol. 46 (2), n. ${ }^{\circ}$ 254, 2015, abril-junio, pp. 79-97 
El paradigma biopsicosocial no ha sido aceptado por todos los agentes. En España, el rechazo más interesante proviene, a mi entender, del Foro de Vida Independiente (FVI), que con su propuesta de diversidad funcional ha radicalizado el paradigma social en la línea que lo hicieran Bill Hughes y Kevin Paterson (1997), para los cuales lo biológico y lo social desaparecen para dar lugar a lo social-hermenéutico, a la soberanía de lo interpretativo, fenomenológico, simbólico.

\section{Discapacidad versus diversidad funcional}

La propuesta del FVI que llaman de la diversidad funcional parte de dos cuestiones evidentes: (i) que la deficiencia física, sensorial, intelectual o del desarrollo es interpretada como una situación no deseada, lo cual lleva a considerar, en algunos casos, que son vidas que es mejor que no sean vividas, por ejemplo cuando una mujer decide abortar por una grave malformación del feto; y (ii) que los valores, principios y derechos proclamados en la Declaración universal de derechos humanos y en todos los textos jurídicos internacionales y nacionales que de ella derivan no se han hecho efectivos en la mayoría de las personas con discapacidad física o sensorial y, sobre todo, intelectual o del desarrollo, que en la mayoría de los casos continúan sufriendo discriminación y vulneración de derechos fundamentales (SOLCOM, 2010, 2011; Palacios, 2008). La novedad de la reflexión del FVI es la relación de causalidad que establecen entre ambos factores: defienden que considerar la deficiencia como una situación peor y no deseada es la principal causa de la discriminación y vulneración de los derechos fundamentales de las personas con discapacidad y que, por lo tanto, la lucha por la igualdad efectiva de derechos debe darse principalmente en la interpretación de lo que consideramos deficiencia, dejando de considerarla como una situación peor y no deseada para verla simplemente como una diversidad.

El modelo de la diversidad funcional gira alrededor de una cuestión básica: las personas no tienen deficiencia, sino diversidad, de lo cual se deduce que lo que sufren no es discapacidad, sino marginación e injusticia debido a su diversidad. Considera que la sociedad no sólo construye la discapacidad, como sostiene el paradigma biopsicosocial, sino también la deficiencia, y que lo que debería ser percibido como otra manera de ser y de hacer las cosas, lo es como un déficit no deseable, como una de-ficiencia y dis-capacidad. Que la deficiencia es un constructo que responde a una concepción antropológica y de la existencia normalizadora, que exalta los modelos estándar de perfección, olvida que todos somos dependientes, vulnerables y finitos y subyuga a aquellos que difieren de la mayoría estadística a través de diferentes estrategias, por ejemplo patologizando sus diferencias. Esta interpretación y relación con lo que difiere, añaden, no solo es la causa de la actual marginación de las personas con discapacidad, sino también de las situaciones de horror y exterminio que caracterizan buena parte de la historia de este colectivo, de lo cual el Tercer Reich es un monstruoso ejemplo.

Para el modelo de la diversidad funcional, el concepto persona con discapacidad no deja de ser el último y más amable de una sucesión de vocablos (monstruo, idiota,

(C) Ediciones Universidad de Salamanca

Siglo Cero, vol. 46 (2), n. ${ }^{\circ}$ 254, 2015, abril-junio, pp. 79-97 
inútil, subnormal, lisiado, retrasado, impedido, inválido, minusválido, disminuido, deficiente, impedido, discapacitado...) que no logran desembarazarse de la mirada negativa hacia este otro diferente, una mirada que es la fuente de su segregación y a veces exterminio. No proponen, por lo tanto, un simple cambio de nombre, sino un proceso de resemantización activista, de crítica, denuncia y deconstrucción de lo que crean las actuales palabras, sustituyéndolas por otras que digan nuevas cosas porque parten y generan nuevas visiones y relaciones (Romañach y Lobato, 2005; Palacios y Romañach, 2006, 2009; Pié, 2012, 2014).

La locución personas con diversidad funcional ha tenido una rápida aceptación en algunos círculos académicos y profesionales y poco a poco parece extenderse. Sin embargo y a excepción de los activistas convencidos de este paradigma, se utiliza la expresión pero no su propuesta social-hermenéutica, y diversidad funcional continúa designando a personas que se considera que tienen una deficiencia orgánica que les provoca dificultades en su interacción con los otros y con el mundo.

Utilizar el concepto diversidad funcional renunciando al paradigma socialhermenéutico del que ha surgido, a unos les puede parecer que solo contribuye a generar confusión o incluso una estupidez y a otros una apropiación traicionera, una muestra más de la logofagia de lo dominante. A los que piensen que debemos dejar de hacer el tonto con las palabras y que, si consideramos que hay discapacidad, debemos hablar de "persona con discapacidad", dejarnos de eufemismos o lenguajes políticamente reconfortantes y no contribuir más a la galopante confusión del lenguaje; a estos, decía, cabría hacernos cuatro consideraciones. La primera, que el lenguaje no solamente describe el mundo, sino que también lo crea; que el pensamiento es lenguaje y la conciencia básicamente lingüística. Y que el concepto persona con discapacidad no logra, aunque lo intenta gramaticalmente, referirse solo a una característica. Situar a la persona en primer lugar y adjetivar la deficiencia no ha logrado evitar que el concepto continúe otorgando una identidad primaria. No es una descripción con la que la persona afectada se encuentra de vez en cuando, como le ocurre a una persona con calvicie o incluso con cáncer, sino que la define e identifica de por vida y en todos los contextos, y lo hace de forma problemática, inferiorizante, sufriente, victimizadora, que es interiorizada por propios y extraños.

Se puede alegar que el nuevo concepto es poco preciso científicamente. La segunda consideración que cabría hacer es que en la identificación de una persona y de un colectivo con problemáticas orgánicas, pero principalmente sociales, no debería dominar lo científico, sino lo socialmente correcto; que persona con diversidad funcional física, sensorial, intelectual o del desarrollo se está utilizando y extendiendo sin que se generen confusiones; y que debería tenerse en cuenta la opinión de aquellos colectivos de personas afectadas que dicen sentirse insultadas cuando se las llama personas con discapacidad.

La tercera consideración que debería hacerse es que, a pesar del acierto del paradigma biopsicosocial de entender la discapacidad como el resultado de la interacción de una deficiencia de la persona con su entorno, la discapacidad continúa refiriéndose a la persona, centrándose en ella. No decimos, por ejemplo, sociedad con discapacidad, interacción con discapacidad o persona con una relación de discapacidad.

(C) Ediciones Universidad de Salamanca

Siglo Cero, vol. 46 (2), n. ${ }^{\circ}$ 254, 2015, abril-junio, pp. 79-97 
Y puesto que, a mi entender, no hemos hallado un concepto científica y socialmente acertado y breve, persona con diversidad funcional me parece correcto.

También se puede alegar que ver solo diversidad donde hay deficiencia y discapacidad puede llevar a situaciones inaceptables, que es la tesis principal de estas páginas. Sin embargo y como cuarta y última consideración, cabe señalar que utilizar, como voy a hacer a partir de aquí, persona o personas con diversidad funcional no comporta abrazar el paradigma social-hermenéutico ni desestimar los conceptos deficiencia y discapacidad, que continúan siendo imprescindibles en algunos contextos lingüísticos. El concepto personas con diversidad funcional me parece acertado, pero no el paradigma social-hermenéutico del que ha surgido y que en estas páginas intento rebatir. No podemos, de momento, dejar de considerar que aquellos a los que se refiere tienen, entre otras muchas características, una deficiencia física, sensorial, intelectual o del desarrollo que, a veces, se convierte en una discapacidad en su interacción con el entorno, pero sí podemos cambiar la locución que los identifica y que contribuye, se quiera o no, a crear una identidad.

Ver solo diversidad en la discapacidad, como pretenden los activistas del FVI y los autores que les dan soporte, tiene consecuencias indeseables. No cabe decir que estoy dispuesto a cambiar de opinión si se resuelven los problemas éticos y epistemológicos que esta cuestión me plantea y que presento, espero que adecuadamente, en estas páginas. Me centro en lo que no comparto del paradigma social-hermenéutico, sin mencionar los aspectos positivos que, sin duda, tiene. Por ejemplo, provocar convulsiones, debates y cambios que las propuestas prudentes no consiguen generar, o lo hacen con demasiada lentitud cuando a quien espera le consumen la vida. También su sugestiva reivindicación, y en algunos casos exaltación y orgullo de lo propio, que contribuye positiva y significativamente a alejar la lástima, la displicencia e incluso el desprecio respecto a otras corporeidades, estéticas, sensorialidades, formas de pensar y de vida. En este sentido, las reflexiones y reivindicaciones del FVI y de otros movimientos afines (por ejemplo, la Asociación de Mujeres No Estándar, la teoría Queer, la Crip Theory, etc.) ejercen una función muy importante.

De los problemas éticos que me plantea el paradigma social, hay dos especialmente relevantes. El primero, que llamaré de protección, es que si lo que ahora consideramos una disfunción es interpretado únicamente como una diversidad orgánica o del desarrollo, sin que sea posible ninguna valoración de si es mejor o peor tenerla, tal como propone el FVI, no se me ocurre ninguna razón para no respetar la decisión de unos padres de no corregir una disfunción física, sensorial, intelectual o del desarrollo a pesar de poder hacerlo con una terapia eficaz, razonable y sin riesgos; o de no evitarla, o incluso de producirla. Desde el paradigma social-hermenéutico, es difícil encontrar razones para lo que hoy consideramos protección ante un mal.

El segundo problema que me plantea, y que llamaré de justicia distributiva, es: ¿Cómo puede justificarse la discriminación positiva desde el paradigma socialhermenéutico? ¿Cómo justificar la necesidad de priorizar y de dedicar más recursos y atenciones, o más investigación médica y tecnológica, a las personas con diversidad funcional respecto a otros colectivos, si se considera que su manera de funcionar no es ni mejor ni peor que las otras?

(C) Ediciones Universidad de Salamanca

Siglo Cero, vol. 46 (2), n. ${ }^{\circ}$ 254, 2015, abril-junio, pp. 79-97 
En el apartado 3 se identifica y delimita el primer problema, lo cual nos obligará a tratar en el apartado 4 la distinción entre lo deseable y lo indeseable, lo beneficioso y lo dañino, lo moral y lo inmoral, que es la condición de posibilidad de los problemas éticos de protección y de justicia distributiva. En el apartado 5 se aborda el problema de justicia distributiva y, finalmente, en el 6, la cuestión epistemológica que a mi modo de ver subyace en todo este debate: si es posible establecer que algunas capacidades físicas, sensoriales, intelectuales y del desarrollo son valiosas, si es posible establecer, en definitiva, que algunas interpretaciones del mundo y de la manera de vivir en él son mejores que otras.

\section{No evitar, no reducir o producir una diversidad funcional}

En un sentido estricto, lo que llamamos diversidad no es algo a tolerar, respetar, proteger o promover necesariamente. Hay diversidades o diferencias que consideramos deseables y otras indeseables. Por ejemplo, la mayoría de la gente considera que son preferibles las actitudes respetuosas y solidarias que las sádicas y asesinas. Sin embargo, el concepto diversidad ha acabado por significar, en la mayoría de los contextos lingüísticos, una variedad que debe tolerarse, respetarse, protegerse o promoverse. No cabe duda de que el paradigma social-hermenéutico que aquí es objeto de crítica utiliza diversidad en este sentido: una variedad de funcionamientos, de cuerpos y de mentes sobre la cual cualquier intento de establecer que los hay mejores o peores deviene un acto arbitrario e incluso una semilla del genocidio.

La mayoría de las personas considera que es mejor poder ver, oír, caminar, hablar, pensar, relacionarse con facilidad con el mundo y con los otros, etc., que no poder hacerlo; y que, por lo tanto, estas capacidades son valiosas y deben preservarse y promoverse en la medida de lo posible. De ahí que, cuando hay una pérdida significativa de estas funciones o capacidades, se añada el prefijo de- ('descenso', 'privación') o dis- ('dificultad', 'anomalía') y se hable de deficiencia y de discapacidad física, sensorial, intelectual o del desarrollo. El paradigma social-hermenéutico niega esta valoración. Considera que no poder hacer las acciones que se han mencionado, o no poder hacerlas plenamente, o hacerlas con dificultad, no es ni mejor ni peor. Que es, simplemente y como ya se ha apuntado, otra manera de hacer las cosas y de vivir, y que considerarlas mejores o peores es una arbitrariedad que solo puede justificar una antropología del superhombre y la imposición del poder de la normalidad.

Antes de continuar, me parece importante distinguir entre funciones y vidas. Considerar que hay funciones que es mejor tener no significa considerar que estas vidas sean mejores. Ver, oír, caminar, hablar, pensar, relacionarse con facilidad con el mundo y con los otros no garantizan una buena vida (cuántas personas han malogrado sus vidas por destacar en algunas funciones), lo cual no significa que no contribuyan a tenerla. Esta diferenciación debería permitir que cuando aquí se hable de funciones o capacidades físicas, sensoriales, intelectuales o del desarrollo valiosas, que es mejor tener, no se lea en ello que hay vidas más o menos válidas o que es mejor tener. Lo uno no conlleva necesariamente lo otro. 
Para refutar la consideración que aquí se defiende de que es mejor disponer de funciones como ver, oír, caminar, hablar, pensar, relacionarse con facilidad con el mundo y con los otros, etc., que no disponer de ellas, no basta con destacar y denunciar, como suele hacer el paradigma social-hermenéutico, la opresión de la autosuficiencia y de la normalidad. No cabe duda de que la exaltación de la autosuficiencia puede llevar a una soledad suicida, pero también la exaltación de la interdependencia, a la cual gusta recurrir el paradigma social, puede llevar a un colectivismo esclavizador, y ello no es razón para renunciar a la autosuficiencia y a la interdependencia. Asimismo y respecto a la normalidad, lo que hace, considera o desea la mayoría de las personas no es en sí mismo algo bueno o malo. La estigmatización de la normalidad no deja de ser un prejuicio adolescente. Hay cosas que son normales y nos encantan (por ejemplo, que los padres quieran a sus hijos), otras que desearíamos que dejaran de ser normales (por ejemplo, el consumo desenfrenado de las sociedades opulentas) y otras que desearíamos que fueran normales (por ejemplo, poder confiar en todo el mundo).

El paradigma social-hermenéutico no supondría ningún problema ético si no pudiéramos influir en las funciones y capacidades de las personas. Uno podría aceptar, o gustarle más o menos, tener o no -o que los otros tuvieran o no- la capacidad de ver, oír, caminar, hablar, pensar, relacionarse, etc., y la discusión podría fácilmente concluir con la logoseada expresión de que entre gustos no hay disputas. Estaríamos supeditados al poder de lo que la naturaleza, los dioses, el destino o el azar imponen sobre nosotros y que no se puede evitar o cambiar. Sin embargo, los humanos podemos influir, y cada vez más, en lo que tenemos y somos, lo cual nos confiere responsabilidad. Hans Jonas dice que el ser humano es el único ser conocido que puede tener responsabilidades, porque tiene poder y libertad. "Quien no puede hacer nada -dice-, no tiene que responsabilizarse de nada; en cierto modo se puede decir pues que aquel que solo tiene una muy escasa influencia en el mundo está en la feliz situación de poder tener una buena conciencia”. Pero quien puede decidir hacer algo, aunque sea decidir no hacer nada, puede elegir entre alternativas de actuación, con lo cual tiene responsabilidades (Jonas, 1985: 177). Así pues, tenemos la responsabilidad de decidir si tener una deficiencia es o no peor que no tenerla, porque en algunos casos tenemos el poder de evitarlas, reducirlas o crearlas.

Ser libre significa distinguir entre lo deseable e indeseable, lo justo e injusto, lo mejor y peor, y poder escoger, lo cual en algunos casos nos confiere una enorme responsabilidad que no es posible eludir. Si considerásemos que la ceguera, la sordera, la parálisis, la trisomía 21 o el síndrome de Turner no son deficiencias, sino simple diversidad, se convertirían en características de las personas que deberíamos preservar y en algunas circunstancias promover. Cualquier intento tecnocientífico de luchar contra estas diversidades se convertiría, efectivamente y como afirma el Disabled People's International Europe (2000a, 2000b) y el FVI, en una aberración, en un genocidio. Sería tanto como luchar contra la homosexualidad o la pigmentación negra de la piel para erradicarlas. Cualquier intento de unos padres de preservar o incluso producir una deficiencia (una diversidad funcional) en sus hijos debería ser respetada. Deberíamos respetar, por ejemplo, que unos padres no autorizasen una intervención quirúrgica eficaz, razonable y sin riesgos que posibilitaría que su hijo pudiera ver, oír,

(C) Ediciones Universidad de Salamanca

Siglo Cero, vol. 46 (2), n. ${ }^{\circ}$ 254, 2015, abril-junio, pp. 79-97 
andar, hablar o pensar; o las fecundaciones in vitro con el fin de implantar un cigoto con trisomía 21, porque desean tener un hijo con esta diversidad.

El enunciado "producir una deficiencia (una diversidad funcional)" puede suscitar escándalo tanto a aquellos que nos situamos en el paradigma biopsicosocial como a los que lo hacen en el social. Respecto a los primeros, es fácilmente comprensible: consideramos que producir una deficiencia es hacer un daño, lo cual es inmoral e injusto si se hace a alguien que no tiene las condiciones para decidir si la desea. Por lo que hace a los segundos, el escándalo, cuando aparece, suele responder a una especie de respeto teologal hacia lo que nos viene dado (por la azarosa naturaleza, el azar o los dioses) y sobre lo cual no nos está permitido interferir. Una adaptación de la sentencia del Eclesiastés $(7,13)$ que, más o menos, rezaría así: "Contempla la diversidad funcional: ¿Quién se atreverá a no mantenerla?”.

Curiosamente, este respeto teologal del paradigma social hacia lo que nos viene dado y ante lo cual no nos está permitido interferir solo se manifiesta en las actuaciones que se dirigen directamente a los cuerpos o mentes de las personas con diversidad funcional a fin de lograr, en la medida de lo posible, una normalización. En cambio, la aparición y aplicación de utensilios y estructuras electrónicas, mecánicas y arquitectónicas que modifiquen el entorno y la relación con él a fin de poder llevar una vida normal son reclamadas y celebradas.

Salvo excepciones, por ejemplo de algunos colectivos de personas sordas, el paradigma social no considera que aquello que la mayoría percibe como deseable, como por ejemplo caminar, ver o razonar cuestiones de una cierta complejidad, sean aptitudes a las que vale la pena renunciar para disfrutar plenamente de las formas propias y diferentes de estar en este mundo y de hacer las cosas. Al contrario, celebra cualquier avance instrumental que permita realizar con la máxima igualdad posible aquello que realiza la mayoría, por ejemplo, a través de las sillas eléctricas, la domótica o los perros guía. Salvo, como se ha dicho, algunos colectivos, no parece que se reivindique otra manera de hacer, sino otra manera de poder hacer las mismas cosas que la mayoría estadística realiza. No se acepta y combate cualquier intervención médica orientada a rehabilitar o corregir el cuerpo o las funciones mentales, pero se exigen intervenciones técnicas orientadas a posibilitar que el cuerpo o la mente puedan realizar aquellas funciones que, por otra parte, parecen considerar deseables por imposición de la mayoría estadística.

\section{La distinción entre beneficioso y dañino, deseable e indeseable, moral e inmoral}

Los problemas éticos de protección y de justicia distributiva antes mencionados son, a mi modo de ver, la principal crítica que se puede hacer al paradigma socialhermenéutico. Ambos problemas son posibles porque aceptamos unos derechos (salud, integridad física y psíquica, igualdad y justicia), de los cuales se derivan unos deberes morales y jurídicos (protección y discriminación positiva). Sin embargo, los deberes de protección y de discriminación positiva solo pueden materializarse identificando qué bienes debemos proteger y qué déficits compensar, lo cual solo es

(C) Ediciones Universidad de Salamanca

Siglo Cero, vol. 46 (2), n. ${ }^{\circ}$ 254, 2015, abril-junio, pp. 79-97 
posible a través de la diferenciación entre lo beneficioso y lo perjudicial, lo deseable y lo indeseable.

Esta diferenciación se establece partiendo de un umbral de bienes considerados básicos, beneficiosos y deseables, a partir del cual todo aquello que se sitúa por debajo deviene dañino e indeseable, en tanto que déficit o pérdida de lo primario o básico, y lo que se sitúa por encima, beneficioso y deseable, en tanto que aumenta la calidad, cantidad o variedad de bienes. Así pues, se configuran tres grandes niveles en la escala de bienes: el básico, el de los daños (situado por debajo de los bienes básicos) y el de los beneficios (situado por encima de los bienes básicos). Estos tres grandes niveles se dan, entre otros, en el ámbito de los bienes materiales y culturales, en el de los bienes físicos, sensoriales, intelectuales y del desarrollo de las personas, en el de la moral y en el de la justicia. Veámoslos uno a uno.

En el ámbito de los bienes materiales y culturales, consideramos que hay unos bienes básicos que es deseable que todos dispongan si quieren (alimentación, vivienda, educación, etc. $)^{3}$, que el hecho de que no lo hagan es algo dañino e indeseable y que el aumento de la cantidad, la calidad o la variedad de ellos es algo beneficioso y deseable ${ }^{4}$. En el de los bienes físicos, sensoriales, intelectuales y del desarrollo de las personas, consideramos que hay unas características básicas (por ejemplo, oír, andar, hablar, pensar, relacionarse con las otras personas, etc.), a partir de las cuales aquellas situaciones o acciones que se sitúan por debajo devienen deficiencias, daños y diversidad no deseable, y las que lo hacen por encima, excelencia, beneficios y diversidad deseable.

En el ámbito de la moral, de las normas que valoran y guían la conducta humana, en el umbral de lo básico, situamos los valores y conductas que se considera necesario y justo que todos, sin excepción, acaten, por ejemplo que la educación que se imparte a los hijos sea respetuosa con los derechos humanos. Este umbral básico ha sido denominado, según sean los autores, ética de mínimos (Cortina, 1993, 1998, 1999, 2001), moralidad (Hegel, 1821), moral (Habermas, 1994, 2002), lo justo (Rawls, 1971, 1993), ética civil o pública (Camps, 2010), etc. Por debajo de esta moral de mínimos o básica, se sitúan aquellos valores y conductas que la sociedad civil considera dañinos, inmorales o injustos, por ejemplo, una educación basada en los maltratos y abusos a la infancia. Por encima de la moral de mínimos o básica, se sitúan los valores y conductas que cada persona puede escoger libremente y que conforman una diversidad que, en las sociedades plurales, consideramos beneficiosa y necesario tolerar, respetar, proteger y, en algunos casos, promover, por ejemplo, las diferentes formas de educación de los hijos. Esta moral de máximos también ha sido llamada ética de máximos, eticidad, ética, lo bueno, ética privada, etc., y la subsunción respecto al umbral básico, la "prioridad de lo justo sobre las ideas de lo bueno" (Rawls, 1988).

3 Entre los principales autores que se han ocupado de los bienes primarios o básicos cabe citar a John Rawls, Ronald Dworkin, Thomas Nagel, Thomas Scanlon, Eva Kittay y Martha Nussbaum.

4 Para no alargar esta exposición, no voy a describir ni analizar aquí las situaciones en las que el aumento de la calidad, la cantidad y la cantidad de bienes se convierte en excesivo, dañino, indeseable e inmoral. 
La conjunción de la escala de bienes materiales y culturales y de la escala de bienes físicos, sensoriales, intelectuales y del desarrollo de las personas, con la escala moral, da lugar a unos bienes jurídicos a proteger. Las acciones que provocan un daño a estos bienes pueden ser consideradas un delito; las personas que no los alcanzan pueden exigir un trato preferencial o discriminación positiva; y las acciones que los protegen o promueven, incluso sin el consentimiento de los afectados, pueden llegar a ser consideradas acciones ética y jurídicamente justificadas en algunas situaciones.

En una sociedad libre, si se reúnen las condiciones de madurez suficientes y afecta a la propia persona, se permite adentrarse en el umbral de lo considerado dañino e indeseable. Uno puede, por ejemplo, considerar que prefiere ser sordo, ciego o parapléjico y decidir no seguir un tratamiento eficaz, razonable y sin riesgos que le permitiría cambiar esta situación; o incluso puede decidir provocarse alguna de estas características en el caso de que no las tuviera. La apotemnofilia, por ejemplo, está considerada un trastorno psíquico (un Desorden de la Identidad de la Integridad Corporal), pero es posible considerar que una persona sin ningún trastorno mental quiera amputarse un dedo por una cuestión estética. La decisión de una persona de no someterse a una intervención que le posibilitaría oír, ver o caminar, o la decisión de una persona libre de amputarse un dedo, deben ser respetadas no porque hayamos colocado los bienes del oído, la vista, la movilidad o la aprehensión en el umbral de los bienes que no consideramos básicos, sino porque aun siendo bienes básicos que la moral de mínimos protege, hay otro bien prima facie básico a proteger y que, en las situaciones descritas, consideramos más importante: la libertad personal. Sin embargo, cuando las voluntades antes expuestas son expresadas por personas sin plena capacidad para entender las consecuencias que dichas acciones tendrían (por ejemplo, niños, personas con enfermedad mental, demencia o discapacidad intelectual), consideramos que prevalecen los bienes prima facie básicos del oído, la vista, la movilidad y la integridad física. Lo mismo ocurre cuando este tipo de decisiones son tomadas por padres o tutores legales respecto a aquellos que deben cuidar, puesto que consideramos que estos bienes básicos no están sometidos al libre arbitrio de los otros.

A algunas personas, toda esta escalimetría les puede resultar artificiosa o extraviada. Pueden incluso recurrir a la fácil consideración de ver en ello una perversa métrica social en la cual clasificar a los seres humanos, más arriba o más abajo, en la escala de los indeseables, los normales y los superhombres. Cuando me refiera a los peligros del continuum abordaré esta posibilidad. Ahora, simplemente decir que incluso aquellos que vean en estas escalas una peligrosa métrica racista u orwelliana no pueden prescindir de ellas en su quehacer cotidiano. Nadie puede vivir ni relacionarse correctamente con los demás sin distinguir -cierto que en un amplio abanico de tonalidades- entre lo beneficioso y lo dañino, lo deseable y lo indeseable, lo mejor y lo peor, lo moral y lo inmoral. A mi modo de ver, el peligro no está en utilizarlas, sino en hacerlo sin saberlo (que es lo que suelen hacer algunos de los que las critican), o en confundirlas o aplicarlas incorrectamente (que es lo que suelen hacer los dogmáticos y los nazis), o en aplicarlas donde no tienen razón de ser.

Hay tres falacias que aquí conviene tener presentes: del continuum, de la pendiente resbaladiza y del post hoc ergo propter hoc. La falacia del continuum considera que

(C) Ediciones Universidad de Salamanca

Siglo Cero, vol. 46 (2), n. ${ }^{\circ}$ 254, 2015, abril-junio, pp. 79-97 
puesto que las diferencias en una secuencia de sucesos o cosas son muy pequeñas, cualquier intento de establecer límites entre ellos es arbitrario y, por lo tanto, que se trata de una y la misma cosa. Es decir, que posiciones extremas conectadas por muchas pequeñas diferencias intermedias son la misma cosa, puesto que no podemos establecer límites objetivos para el cambio. La falacia de la pendiente resbaladiza considera que desde un comienzo aparentemente inocuo se llega inevitablemente a un final claramente indeseable o espantoso, y que esto se hace a través de una cadena de inferencias del tipo "A causará inevitablemente B, B causará inevitablemente C, C causará inevitablemente D, etc.”. Finalmente, la falacia post hoc ergo propter hoc ("Después de esto, por lo tanto a consecuencia de esto"), que a veces y para abreviar suele denominarse falacia post hoc, considera que la sucesión temporal de dos fenómenos implica que el primero es la causa del segundo, lo cual por sí mismo no es evidente. Que la noche anteceda al día no significa que aquélla sea la causa de éste.

Los argumentos del paradigma social-hermenéutico no caen en las falacias señaladas (si lo hicieran, muchos de los argumentos en su contra que en estas páginas se intentan aportar serían innecesarios), pero en algunas ocasiones se aproximan a ellas. Considerar mejor poder caminar que no poder hacerlo, o considerar mejor no tener una disfunción intelectual que tenerla, no lleva necesariamente al holocausto; también lleva, por ejemplo, a preocuparse por estas personas y a ofrecerles recursos y atenciones que no damos a otras diversidades. A un lado no hay el paradigma social y al otro, todos aquellos que, de una manera u otra, generan y participan de la vulneración de derechos de las personas con diversidad funcional, ya sea a través de un ingenuo y buenista colaboracionismo o de un nazismo manifiesto. Indignarse por la situación pasada y actual de las personas con diversidad funcional, denunciar su situación y luchar por sus derechos no requiere abrazar el paradigma social-hermenéutico.

El paradigma social-hermenéutico suele insistir en que todos tenemos alguna deficiencia y discapacidad, que todos somos vulnerables y que, por lo tanto, cualquier intento de establecer límites, agrupamientos o grados es una arbitrariedad. Este argumento también se utiliza para inhabilitar el concepto dependencia: no cabe hablar de personas dependientes, porque todas lo somos, todos dependemos de los otros, nadie se libra de, en algún momento de su vida, experimentar de forma radical la dependencia respecto de los otros. Nos hallamos pues, concluyen, ante una y la misma cosa y cualquier intento de establecer límites, agrupamientos o grados de dependencia es un acto arbitrario, un escape, una entelequia. La cuestión de la igualdad ante la finitud, la contingencia, la fragilidad y la interdependencia de la vida abre horizontes importantísimos y muy fructíferos en ética; sin embargo, me temo que cuando se utiliza para rechazar el intento de establecer diferenciaciones entre las capacidades deviene una falacia del continuum que impide distinguir los distintos grados de dependencia.

Esta incapacidad de marcar diferencias entre lo que se concibe como un continuum también la encontramos en el hilo conductor que, dicen, une a la mujer que se realiza una amniocentesis para poder abortar en caso de que se diagnostique una anomalía cromosómica en el feto, hasta los hornos crematorios de Auschwitz; o entre el médico que investiga, con rigor y sensibilidad ética, la forma de curar la parálisis cerebral,

(C) Ediciones Universidad de Salamanca

Siglo Cero, vol. 46 (2), n. ${ }^{\circ} 254,2015$, abril-junio, pp. 79-97 
hasta los experimentos del nazi Josef Mengele. ¡Claro que hay fundamentos que comparten! Sin embargo, para considerar a Mahatma Gandhi una versión reducida de Adolf Hitler, no es suficiente con alegar que los dos compartían la posibilidad de pensar que otro mundo era posible. Los continuum poco fundamentados de extremos tan alejados no pasarían de ser análisis superficiales si no fueran un improperio para la mujer que se realiza la amniocentesis y, sobre todo, para las víctimas de Auschwitz.

\section{¿Cómo justificar la discriminación positiva?}

La negación de la deficiencia física, sensorial, intelectual o del desarrollo puede justificar, a pesar o precisamente por su radical mirada igualitarista, situaciones que, desde el paradigma biopsicosocial, serían claramente injustas. Hacer diferencias y establecer lo que es mejor o peor no es necesariamente malo, sino a veces absolutamente necesario: deviene el fundamento del principio de justicia que nos permite establecer prioridades y tratar de diferente forma situaciones o necesidades distintas. Nos permite, por ejemplo, considerar que, cuando los recursos son escasos, es justo priorizar las intervenciones quirúrgicas que evitan la ceguera (evitar un daño) e injusto priorizar las intervenciones de cirugía plástica cuyo único fin es aumentar todavía más el encanto de una persona (producir un beneficio). Nos permite, por ejemplo, considerar justo dedicar más recursos a los niños con dificultades de aprendizaje que a los que no las tienen. Y todo esto porque nos es posible considerar que ser ciego o tener dificultades de aprendizaje no es solamente tener un cuerpo o una mente diversa, u otra manera de funcionar igual de válida que las otras, sino tener unas capacidades de funcionamiento que consideramos peores, deficitarias y que, por lo tanto, necesitan más atención.

Las políticas de discriminación positiva solo son posibles a partir, al menos, de estas tres consideraciones: (i) distinción: la diferenciación de unas situaciones respecto a otras ("La situación $x$ es distinta que la situación $y$ ”); (ii) valoración: la valoración de que unas situaciones son peores que otras y que, por lo tanto, se produce una desigualdad ("La situación $x$ es peor que la situación $y$ ”); y (iii) moralidad o justicia: una conciencia moral según la cual las personas en situación de desventaja o desigualdad deben ser ayudadas y favorecidas ("Se deben dedicar más recursos y atenciones a las personas que se hallan en la situación $x$ que a las que se hallan en la situación $y$ ”). Adviértase que son tres condiciones graduales o acumulativas: para que se dé la segunda debe darse la primera, y para que se dé la tercera debe darse la segunda. Así pues, para dar más recursos y atenciones a una persona debe considerarse que tiene una situación distinta (distinción), que esta situación distinta es más desfavorable (valoración) y que no hacer nada para remediarlo es una injusticia, o algo incorrecto (moralidad o justicia).

El paradigma social-hermenéutico no niega las tres condiciones señaladas de distinción, valoración y moralidad o justicia, pero difiere profundamente en el contenido de la segunda, lo que afecta significativamente el de la tercera. Considera (i) que los cuerpos y mentes de las personas con diversidad funcional física, sensorial, intelectual o del desarrollo son distintos y tienen otra manera de funcionar (distinción), pero (ii) que esta distinción no es en sí misma peor respecto a otros funcionamientos

(C) Ediciones Universidad de Salamanca

Siglo Cero, vol. 46 (2), n. ${ }^{\circ}$ 254, 2015, abril-junio, pp. 79-97 
posibles, sino únicamente en la mirada e interpretación del grupo dominante (valoración), lo cual (iii) genera situaciones de injusticia que deben remediarse (moralidad o justicia). Para el paradigma social-hermenéutico, si se consiguiera ver la disfunción simplemente como una diversidad que no es ni mejor ni peor que las otras, se provocaría o forzaría irremediablemente la desaparición de la injusticia. Sin embargo, en esta situación no veo qué razones habría para dedicar mayores recursos y atenciones a la diversidad funcional que al resto. El paradigma social-hermenéutico no duda en considerar que son necesarios más recursos y atenciones hacia su diversidad que hacia otras, sin justificar por qué y sin que nadie se lo demande, lo cual es posible porque continuamos viendo, aunque no únicamente, disfunción y discapacidad en la diversidad funcional.

En esta cuestión, no deja de ser curioso que el paradigma social-hermenéutico se acerque a la teoría de la justicia entendida como estricta equidad, una teoría que, como el mismo John Rawls admitió (1993: 50-52), tiene dificultades en justificar lo que se les debe a las personas con diversidad funcional. Como se sabe, Martha C. Nussbaum (2001: 108; 2006: 42) ha intentado corregir este déficit de la teoría de la justicia como equidad, a través del enfoque de las capacidades humanas, que ahondan precisamente en las diferencias existentes entre aquello que las personas son efectivamente capaces de hacer y de ser. Esto la obliga a recurrir a la idea de las capacidades básicas y al umbral básico para cada capacidad, a partir del cual es posible establecer las capacidades y, por lo tanto, las personas que están en una situación desfavorable y requieren mayor atención en una sociedad que se quiere justa, entre las cuales sitúa la diversidad funcional.

Para ilustrar que las discapacidades físicas, sensoriales, intelectuales o del desarrollo no son distintas a otras formas de incapacidad que consideramos propias de la diversidad, los defensores del paradigma social-hermenéutico suelen recurrir a ejemplos e interrogantes del tipo: "Un ciudadano queda retenido en un aeropuerto internacional por no saber inglés, mientras que otro con esclerosis múltiple, que domina este idioma y que viajaba en el mismo avión, visita la ciudad. ¿Quién es aquí el 'discapacitado'?”. Éste y muchos ejemplos parecidos sirven para sensibilizarnos sobre cuestiones que suelen pasar desapercibidas, pero también pueden provocar confusiones. No cabe duda de que, en la situación descrita, la persona que tiene dificultades es la que no sabe inglés. Pero incluso en estos casos nos vemos en la necesidad de determinar: primero, que cuando se viaja es mejor saber inglés que no saberlo; y segundo, cuál de las dos situaciones (no saber inglés o tener esclerosis múltiple) es peor y, por lo tanto, a cuál de los dos colectivos debemos atender primero, o dedicarle proporcionalmente más recursos. Si los recursos son escasos, ¿a qué los dedicaremos? ¿A que en los aeropuertos haya traductores de todos los idiomas posibles o a facilitar los medios técnicos y arquitectónicos para que las personas con esclerosis múltiple puedan viajar? No creo que las personas con diversidad funcional física, sensorial, intelectual o del desarrollo consideren justo tratar en igualdad de condiciones su diversidad que la diversidad de aquellos que no saben inglés. Considerar que no saber inglés no es ni mejor ni peor que tener una esclerosis múltiple puede ser muy ofensivo e injusto para aquellas personas que padecen esta enfermedad.

(C) Ediciones Universidad de Salamanca

Siglo Cero, vol. 46 (2), n. ${ }^{\circ} 254,2015$, abril-junio, pp. 79-97 


\section{Algunas interpretaciones son mejores que otras}

No cabe duda de que la discriminación y vulneración de derechos hacia las personas con diversidad funcional parte de nuestra relación con lo que difiere y de que es absolutamente necesario ver de otra forma al otro diferente. Sin embargo, no basta con ver de otra forma, porque, desgraciadamente, hay algo a lo que solemos llamar realidad que a veces se empeña en permanecer inalterable a nuestra interpretación.

El paradigma social-hermenéutico afirma que la deficiencia es una construcción social. Por lo tanto, considera que la solución al problema que afecta a este colectivo pasa por ver diversidad donde ahora vemos deficiencia, y tratarla como tal. La famosa sentencia nietzscheana "No hay hechos, solo interpretaciones. Y esto es una interpretación" (Nietzsche, 1886-1887: 7[60]) resume muy bien el fundamento de esta propuesta de construcción y deconstrucción humana de la realidad. Sin embargo y lamentablemente, sabemos que hay hechos, algunos de los cuales se resisten a desaparecer o incluso a apaciguarse por más que intentemos interpretarlos de otra manera. Interpretar de muchas y variadas maneras la bomba que acaba de explotar no evita la masacre acontecida. Paul Veyne dijo que la historia existe "solo en relación a las preguntas que le planteamos" (Veyne, 1976), lo cual es cierto. Sin embargo, no preguntarse por las personas asesinadas o vilipendiadas, no escribir su historia no hace que la tragedia no ocurriera. La sentencia de Nietzsche acierta en algunas cosas y en otras deviene sarcástica. Más allá de la simpatía que siento por ella por los horizontes que abre, considero que debería substituirse por esta otra: "Los hechos son interpretados, algunas interpretaciones producen hechos, y algunas interpretaciones son mejores que otras, por ejemplo ésta".

No hay duda de que las interpretaciones construyen realidades, pero no todas, porque también hay un mundo al que llamamos realidad que es objeto de interpretaciones. Asimismo, no todas las interpretaciones y realidades valen lo mismo. Como se ha señalado hasta la saciedad, que algunas interpretaciones son mejores que otras no lo puede poner en duda nadie sin caer en una contradicción. A lo máximo que se puede aspirar es a decir: "No hay ninguna interpretación mejor que otra excepto ésta". Y respecto a las realidades, que algunas son mejores que otras tampoco lo puede poner en duda nadie, al menos nadie que haya sufrido de verdad o que haya catado la felicidad.

De entre las principales causas de la mirada del déficit que caracterizan nuestra percepción y trato con las personas con diversidad funcional, el paradigma socialhermenéutico destaca, como se ha dicho, la imposición de la normalidad y la dificultad de aceptar la diferencia. Alegan, y no les falta razón, que la historia ha demostrado que los patrones de normalidad son arbitrarios, cambiantes y estigmatizadores con la diferencia, como ha sucedido, por ejemplo, con las personas homosexuales, que han sido consideradas -y lamentablemente lo son aún para algunos- seres deficientes a los que había que rehabilitar a través de la moral o la medicina, porque no respondían a los cánones de normalidad sexual. Sin embargo, lo que les ocurrió a las personas homosexuales no tiene que ser necesaria y exactamente lo mismo que les ocurre a las personas con diversidad funcional. 
La prueba de que hay realidades creadas por las interpretaciones la tenemos en que, allí donde la interpretación de la homosexualidad varía, los problemas de la homosexualidad desaparecen. Y la prueba de que hay realidades que se resisten a desaparecer por más que las interpretemos de distinta forma es que, allí donde se interpreta de distinta forma la deficiencia, algunos problemas de ella persisten. No cabe duda de que la interpretación de la disfunción física, sensorial, intelectual o del desarrollo influye significativamente en la forma de vivirla y en el trato a las personas que la tienen. Sin embargo y lamentablemente, estas disfunciones no son solo un discurso históricamente construido que pueda deconstruirse todo él con la palabra. Ver solo diversidad donde ahora también vemos disfunción no resuelve todas las problemáticas. Los cuerpos y mentes de las personas con diversidad funcional, sobre todo si son muy graves, no están capturados solo por la imposición interpretativa. ¡Ojalá fuera así de sencillo! Ojalá con solo deconstruir, desnaturalizar, resemantizar, desestandarizar... nuestra interpretación de los cuerpos y las mentes de las personas con diversidad funcional, éstas pudieran llevar una vida sin las dificultades que la mayoría de la gente no tienen.

En 1948, Roger G. Barker escribió que "la persona con discapacidad motora está en una posición que no es diferente de la del negro, el judío y cualquier otra minoría racial o religiosa poco favorecida" (Barker, 1948: 31). No cabe duda de que todas estas personas han compartido o en algunos casos comparten aún problemáticas comunes de marginación. Sin embargo, y como se ha repetido a lo largo de estas páginas, para que las personas con diversidad funcional física, sensorial, intelectual y del desarrollo puedan tener una vida en igualdad de condiciones que las personas negras, judías o pertenecientes a minorías raciales o religiosas, hace falta algo más que un profundo cambio en las estructuras sociales e interpretativas. Es necesario también algo que los activistas del paradigma social-hermenéutico niegan pero abrazan: el avance de la ciencia y la tecnología que compense déficits y disfunciones.

A pesar de los logros que las teorías posmodernas nos permiten, debo reconocer que Habermas $(1980,1985)$ acertó cuando dijo que tenían dos debilidades. La primera, un tipo de idealismo lingüístico que las lleva a sobrevalorar el significado de las gramáticas y vocabularios en la constitución de realidades sociales. Y la segunda, la deficiente comprensión de las conquistas universalistas de la modernidad, que las lleva a renunciar a los criterios que nos permiten distinguir las conquistas universalistas de los rasgos colonizadores de la modernidad; a la imposibilidad de diferenciar entre discursos que se imponen debido a sus evidencias (discursos convincentes), por ejemplo, los derechos humanos y la tecno-ciencia, y los discursos que se imponen debido a las coacciones del sistema (discursos colonialistas), por ejemplo, el paternalismo o el desprecio hacia las personas con diversidad funcional.

\section{Referencias bibliográficas}

BArker, R. G. (1948). The social psychology of physical disability. Journal of Social Issue, 4 (4), 28-42.

Campbell, J. y Oliver, M. (1996). Disability Politics: Understanding Our Past, Changing Our Future. Londres: Routledge. 
Camps, V. (2010). El declive de la ciudadanía. La construcción de una ética pública. Boadilla del Monte: PPC.

Casado, D. (2001). Conceptos sobre la discapacidad. Apuntes. Boletín del Real Patronato sobre Discapacidad, 50, 5-13.

Cortina, A. (1993). Ética aplicada y democracia radical. Madrid: Tecnos.

Cortina, A. (1998). Hasta un pueblo de demonios. Ética pública y sociedad. Madrid: Taurus.

Cortina, A. (1999). Ciudadanos como protagonistas. Barcelona: Galaxia Gutenberg/Círculo de Lectores.

Cortina, A. (2001). Alianza y contrato. Política, ética y religión. Madrid: Trotta.

Crespo, M. C., Campo, M. y Verdugo, M. Á. (2003). Historia de la clasificación internacional del funcionamiento de la discapacidad y de la salud (CIF): Un largo camino recorrido. Siglo Cero, 34 (1), 20-26.

Disabled People's International Europe (DPI-Europe) (2000a). El derecho a vivir y ser diferentes. Recuperado de http://www.forovidaindependiente.org.

Disabled People's International Europe (DPI-Europe) (2000b). Las personas con discapacidad hablan de la nueva genética. Recuperado de http://www.forovidaindependiente.org.

Dejong, G. (1979). The Movement for Independent Living: Origins, Ideology and Implications for Disability Research. Michigan State University, UCIR.

Habermas, J. (1980). La modernidad: un proyecto inacabado. En Ensayos políticos (pp. 265283). Barcelona: Península.

Habermas, J. (1985). El discurso filosófico de la modernidad. Madrid: Taurus.

Habermas, J. (1994). Derechos humanos y soberanía popular: las versiones liberal y republicana. En F. Ovejero, J. L. Martí y R. Gargarella (Comps.), Nuevas ideas republicanas. Autogobierno y libertad (pp. 191-206). Barcelona: Paidós.

Habermas, J. (2002). El futuro de la naturaleza bumana ¿Hacia una engenesia liberal? Barcelona: Paidós.

Hegel, G. W. F. (1821). Principios de filosofía del derecho o Derecho natural y ciencia política. Barcelona: Edhasa.

Hughes, B. y Paterson, K. (1997). El modelo social de la discapacidad y la desaparición del cuerpo. Hacia una sociología del impedimento. En L. BARTon (Comp.), Superar las barreras de la discapacidad (pp. 107-122). Madrid: Morata.

Jonas, H. (1985). Técnica, medicina y ética. Sobre la práctica del principio de la responsabilidad. Barcelona: Paidós.

Ley 1/2009, de 25 de marzo, de reforma de la Ley de 8 de junio de 1957, sobre el Registro Civil, en materia de incapacitaciones, cargos tutelares y administradores de patrimonios protegidos, y de la Ley 41/2003, de 18 de noviembre, sobre protección patrimonial de las personas con discapacidad y de modificación del Código Civil, de la Ley de Enjuiciamiento Civil de la normativa tributaria con esta finalidad (2009).

Longmore, P. y Umansky, L. (2000). The New Disabitity History: American Perspectives. Nueva York: New York University Press.

Luckasson, R., Borthwick-Duyl, S., Buntinx, W. H. E., Coulter, D. L., Craig, E. M., Reeve, A., Schalock, R. L., Snell, M. E., Spitalnik, D. M., Spreat, S. y Tasse, M. J. (2002). Mental retardation: Definition, classification, and systems of supports (10. ed.). Washington, DC: American Association on Mental Retardation.

Nietzsche, F. (1886-1887). Fragmentos póstumos, volumen IV (1885-1889). Madrid: Tecnos.

Nussbaum, M. C. (2001). Las mujeres y el desarrollo humano. Barcelona: Herder. 
Nussbaum, M. C. (2006). Las fronteras de la justicia. Consideraciones sobre la exclusión. Barcelona: Paidós.

Nussbaum, M. C. (2011). Crear capacidades. Propuesta para el desarrollo humano. Barcelona: Paidós.

Organización Mundial de la SAlud (OMS) (1980). Clasificación Internacional de Deficiencias, Discapacidades y Minusvalías (CIDDM). Madrid: Ministerio de Asuntos Sociales.

Organización Mundial de la SAlud (OMS) (2001). Clasificación Internacional del Funcionamiento, de la Discapacidad y de la Salud (CIF). Recuperado de http://www. imserso.es/InterPresent2/groups/imserso/documents/binario/435cif.pdf.

Organización de Naciones Unidas (ONU) (2006). Convención sobre los derechos de las personas con discapacidad.

Palacios, A. (2008). El modelo social de discapacidad: orígenes, caracterización y plasmación en la Convención Internacional sobre los Derechos de las Personas con Discapacidad. Madrid: Cinca.

Palacios, A. y Romañach, J. (2006). El modelo de la diversidad: la Bioética y los Derechos Humanos como herramientas para alcanzar la plena dignidad en la diversidad Funcional. Recuperado de http://www.asoc-ies.org/diversitas/docs/modelo\%20diversidad.pdf.

PIÉ, A. (Coord.) (2012). Deconstruyendo la dependencia. Propuestas para una vida independiente. Barcelona: Editorial UOC.

PIÉ, A. (2014). Por una corporeidad postmoderna. Nuevos tránsitos sociales y educativos para la interdependencia. Barcelona: Editorial UOC.

Puig de la Bellacasa, R. (1990). Concepciones, paradigmas, y evolución de las mentalidades sobre la discapacidad. En Discapacidad e Información (pp. 57-90). Madrid: Real Patronato de Prevención y Atención a las Personas con Minusvalía.

Rawls, J. (1971). Teoría de la justicia. Madrid: FCE.

Rawls, J. (1988). The Priority of Right and Ideas of the Good. Philosophy and Public Affairs, vol. 17, n. ${ }^{\circ} 4$ (Autumn, 1988), 251-276.

RAwLs, J. (1993). El liberalismo político. Barcelona: Crítica.

Romañach, J. (2009). Bioética al otro lado del espejo. La visión de las personas con diversidad funcional y el respeto a los Derechos Humanos. A Coruña: Ediciones Diversitas-AIES. Recuperado de http://www.diversocracia.org/docs/Bioetica_al_otro_lado_del_espejo.pdf.

Romañach, J. y Lовато, M. (2005). Diversidad funcional, nuevo término para la lucha por la dignidad en la diversidad del ser humano. Recuperado de http://www. forovidaindependiente.org.

Schalock, R. L. (2007). El nuevo concepto de retraso mental: comprendiendo el cambio al término discapacidad intelectual. Siglo Cero, 38 (4), 224, 5-20.

Schalock, R. L., Borthwick-Duffy, S. A., Bradley, V., Buntix, W. H. E., Coulter, M. D., Craig, E. M., Gomez, S. C., Lachapelle, Y., Luckasson, R., Reeve, A., Shogren, K. A., Snell, M. E., Spreat, S., Tassé, M. J., Thompson, J. R., Verdugo, M. Á., Wehmeyer, M. L. y Yeager, M. H. (2010). Intellectual disability. Definition, Classification, and Systems of Supports. 11th Edition. Washington, D.C.: American Association on Intellectual and Developmental Disabilities.

SeOAne, J. A. (2011). La convención de la ONU sobre los derechos de las personas con discapacidad: perspectiva jurídica. Siglo Cero, 42 (237), 21-32.

SOLCOM (2010). Informe SOLCOM. Derechos humanos en España. Violaciones en España de la Convención sobre los Derechos humanos de las personas con discapacidad

(C) Ediciones Universidad de Salamanca

Siglo Cero, vol. 46 (2), n. ${ }^{\circ} 254,2015$, abril-junio, pp. 79-97 
(diversidad funcional) de la ONU. Recuperado de http://www.asociacionsolcom.org/files/ documentos/Informe_SOLCOM_2010.pdf.

SOLCOM (2011). Informe SOLCOM. Derechos humanos en España. Violaciones en España de la Convención sobre los Derechos humanos de las personas con discapacidad (diversidad funcional) de la ONU. Recuperado de http://www.asociacionsolcom.org/files/documentos/ informe_solcom_2011.pdf.

Verdugo, M. Á. y Schalock, R. L. (2010). Últimos avances en el enfoque y concepción de las personas con discapacidad intelectual. Siglo Cero, 41 (4), 236, 7-21.

Veyne, P. (1976). L'inventaire des différences: leçon inaugurale au Collège de France. París: Seuil.

Wehmeyer, M. L., Buntinx, W. H. E., Lachapelle, Y., Luckasson, R. A., Schalock, R. L. y Verdugo, M. Á. (2008). El constructo de discapacidad intelectual y su relación con el funcionamiento humano. Siglo Cero, 39 (3), 227, 5-18. 